\title{
EMSY overexpression disrupts the BRCA2/RAD51 pathway in the DNA-damage response: implications for chromosomal instability/recombination syndromes as checkpoint diseases
}

\author{
Isabelle Cousineau • Abdellah Belmaaza
}

Received: 2 December 2010/ Accepted: 27 February 2011/Published online: 16 March 2011

(C) The Author(s) 2011. This article is published with open access at Springerlink.com

\begin{abstract}
EMSY links the BRCA2 pathway to sporadic breast/ovarian cancer. It encodes a nuclear protein that binds to the BRCA2 $\mathrm{N}$-terminal domain implicated in chromatin/transcription regulation, but when sporadically amplified/overexpressed, increased EMSY level represses BRCA2 transactivation potential and induces chromosomal instability, mimicking the activity of $B R C A 2$ mutations in the development of hereditary breast/ovarian cancer. In addition to chromatin/transcription regulation, EMSY may also play a role in the DNA-damage response, suggested by its ability to localize at chromatin sites of DNA damage/ repair. This implies that EMSY overexpression may also repress BRCA2 in DNA-damage replication/checkpoint and recombination/repair, coordinated processes that also require its interacting proteins: PALB2, the partner and localizer of BRCA2; RPA, replication/checkpoint protein $\mathrm{A} ;$ and RAD51, the inseparable recombination/repair enzyme. Here, using a well-characterized recombination/ repair assay system, we demonstrate that a slight increase in EMSY level can indeed repress these two processes independently of transcriptional interference/repression. Since EMSY, RPA and PALB2 all bind to the same BRCA2 region, these findings further support a scenario
\end{abstract}

Communicated by A. Aguilera.

I. Cousineau $\cdot$ A. Belmaaza

Department of Microbiology and Immunology, Faculty of

Medicine, Université de Montréal, Montréal, QC, Canada

I. Cousineau · A. Belmaaza ( $\square)$

Centre de recherche, Centre hospitalier de l'Université de Montréal (CRCHUM), Hôpital Notre-Dame, Institut du Cancer de Montréal, 1560, rue Sherbrooke est, Pavillon J.A. de Sève, Y-5634, Montréal, QC H2L 4M1, Canada

e-mail: abdellah.belmaaza@umontreal.ca wherein: (a) EMSY amplification may mimic BRCA2 deficiency, at least by overriding RPA and PALB2, crippling the BRCA2/RAD51 complex at DNA-damage and replication/transcription sites; and (b) BRCA2/RAD51 may coordinate these processes by employing at least EMSY, PALB2 and RPA. We extensively discuss the molecular details of how this can happen to ascertain its implications for a novel recombination mechanism apparently conceived as checkpoint rather than a DNA repair system for cell division, survival, death, and human diseases, including the tissue specificity of cancer predisposition, which may renew our thinking about targeted therapy and prevention.

Keywords Tumor-suppressor genes · Oncogenes · Development/abortion · Aging · Estrogens

\section{Introduction}

$E M S Y$ amplification in sporadic breast and ovarian cancer mimics the activity of $B R C A 2$ mutations in the development of this disease's hereditary form (Hughes-Davies et al. 2003). EMSY encodes a large nuclear protein that binds to the BRCA2 N-terminal domain encoded by exon 3 of the $B R C A 2$ gene $\left(B R C A 2_{\mathrm{ex} 3}\right)$. Adjacent to the EMSY N-terminal domain that interacts with $\mathrm{BRCA} 2_{\mathrm{ex} 3}$ reside conserved residues that specifically bind chromatin-remodeling HP1 $\beta$ and BS69 proteins, implicating EMSY in chromatin regulation. Whereas $\mathrm{BRCA} 22_{\mathrm{ex} 3}$ possesses intrinsic histone acetyltransferase (HAT) activity, chromatin-relaxation activity required for transcription, replication and recombination/repair, HP1 $\beta$ binds to methylated histones involved in chromatin assembly that usually impedes these processes. A role for EMSY in chromatin regulation is also suggested 
by the findings that overexpression of a truncated form of $E M S Y$ represses the transactivation potential of $\mathrm{BRCA} 22_{\operatorname{ex} 3}$ and induces chromosomal instability (CIN), implicating BRCA2 in the development of non-familial cancer as well (Hughes-Davies et al. 2003; Raouf et al. 2005).

However, BRCA $2_{\mathrm{ex} 3}$ may also be directly involved in the maintenance of chromosomal stability through its interaction with RPA, single-strand DNA (ssDNA)-binding replication protein $\mathrm{A}$, and PALB2, two proteins required for development of the DNA-damage response (DDR), including BRCA2/RAD51-mediated homologous recombination (HR) repair of DNA double-strand breaks (DSBs) (Wong et al. 2003; Xia et al. 2006), a well-established function of BRCA2 (Thorslund and West 2007; Moynahan and Jasin 2010). Generally, DSBs, such as those generated by mega-endonucleases (i.e., I-SceI), ionizing radiation (IR), DNA cross-linking agents or by overexpressing oncogenes, activate the DDR orchestrated by PIKKs, the serine/threonine PI3K-like kinases ATM, ATR and DNA$\mathrm{PK}$, which, once recruited/localized at sites of such lethal damage, trigger a cascade of phosphorylation events in several downstream target proteins that coordinate DNAdamage checkpoints (i.e., cell-cycle arrest) with recombination/repair or activate p53-dependent or -independent apoptosis/senescence (Shiloh 2003; Kastan and Bartek 2004; Harper and Elledge 2007; Branzei and Foiani 2008; Halazonetis et al. 2008).

Briefly, while PALB2 links BRCA2 to BRCA1, which localizes PALB2/BRCA2/RAD51 complex at chromatin and I-SceI/IR-induced DSBs (Xia et al. 2006; Zhang et al. 2009), RPA coats ssDNA and recruits ATR through its interacting protein ATRIP, after the localization of activated ATM and the processing of DSB ends into ssDNA by BRCA1 and MRE11/RAD50/NBS1 (MRN) complex (Kastan and Bartek 2004; Jazayeri et al. 2006). In addition, through its interaction with MRN, RPA also recruits ATR/ ATRIP to ssDNA tracts at stalled forks, generated spontaneously or induced by ultraviolet (UV) light, hydroxyurea (HU) or methyl methane sulfonate (MMS) (Harper and Elledge 2007; Olson et al. 2007). MRN is the DNAbinding/bridging/unwinding/exonuclease component of BRCA1-associated genome surveillance complex (BASC) that also contains BARD1 (BRCA1-associated ring domain), ATM, ATR, the DNA-helicase BLM, and replication factors that load DNA-polymerase processivity factor proliferating cell nuclear antigen (PCNA) on the forks (Wang et al. 2000; Greenberg et al. 2006). BRCA1/ MRN not only localizes ATM, ATR and BRCA2/RAD51 complexes at sites of DNA damage, but also facilitates the ability of ATR and ATM to interact with and phosphorylate several downstream targets, most notably, their proximal effector checkpoint-kinases CHK1 and CHK2, respectively, and the cohesin subunit SMC1 (structural maintenance of chromosome 1). Whereas CHK1 and CHK2 target the cyclin-dependent kinases CDK1 and CDK2 for inactivation, thereby imposing G1/S and G2/M checkpoints, SMC1 enhances sister chromatid (SC) cohesion (SCC) to keep them perfectly aligned for BRCA2/ RAD51-mediated HR, thus ensuring error-free repair of DNA damage, replication-fork progression and SC segregation, thereby maintaining chromosomal stability in both structure and number (Shiloh 2003; Kastan and Bartek 2004; Branzei and Foiani 2008; Moynahan and Jasin 2010).

In addition to RPA and PALB2, evidence indicates that BRCA2 may also employ EMSY in DDR development. (a) The inherited, cancer-eliciting $\mathrm{BRCA} 2_{\mathrm{ex}} 3$ mutations that inactivate its transactivation potential and block its binding to EMSY (Hughes-Davies et al. 2003) also abrogate its interaction with RPA (Wong et al. 2003) and PALB2 (Xia et al. 2006); (b) EMSY localizes to IRinduced DNA damage/repair foci (Hughes-Davies et al. 2003) in a manner similar to BRCA2 co-localizing with BRCA1, BARD1, MRN, RPA, RAD51 and ATR at UVstalled forks, marked by PCNA (Scully and Livingston 2000); (c) EMSY-interacting HP1 $\beta$ protein binds to CAF1 , the histone chaperone chromatin-assembly factor that interacts with PCNA (Groth et al. 2007), and like BRCA2, CAF-1 also stabilizes replication forks; in its absence, stalled forks can collapse into DSBs (Lomonosov et al. 2003; Ye et al. 2003). CAF-1/PCNA ensures the loading of acetylated histones behind replication forks (Groth et al. 2007), whereas BRCA2 may use EMSY/HP1 $\beta$ to provide such histones by displacing nucleosomes ahead of such forks, allowing fork movement and RPA coating of nascent ssDNA and recruiting/activating ATR; and (d) overexpression of a truncated form of EMSY in human mammary epithelial cells induces SC-type abnormalities displayed by BRCA2-deficient cells (Raouf et al. 2005). Collectively, these findings raise the hypothesis that increased EMSY level may mimic BRCA2 deficiency in CIN, at least by overriding RPA and PALB2.

To gain insights into this scenario, we increased EMSY level in sporadic breast cancer MCF-7 cells and determined whether it induces other phenotypes of BRCA2 deficiency. In addition to SC-type abnormalities [quadri-radial chromosomes, breakage, tri-radial chromosomes, chromosome loss/gain (aneuploidy/polyploidy), deletions, amplifications, inversions, and translocations], BRCA2-deficient cells also exhibit (a) a deficit in HR repair of I-SceI-induced DSBs; (b) normal efficiency of DSB repair by the error-prone, nonhomologous end joining (NHEJ) pathway; (c) heightened efficiency of DSB repair by ssDNA annealing (SSA), a RAD51-independent gene deletion process restricted to DSBs generated between direct repeats; (d) hypersensitivity to MMS, HU, UV, IR and chemotherapeutic, DSB-inducing 
agents; (e) defective G2/M checkpoint; (f) an amplified rate of both gene mutations and reversions; (g) a hyper-recombination phenotype, characterized by an increased rate of spontaneous HR, gene conversion, inversion and deletion/ amplification (crossover) events; and last but not least (h) an augmented rate of spontaneous SC replication slippage (SCRS), a RAD51-independent gene deletion/amplification process (Scully and Livingston 2000; Venkitaraman 2002; Abaji et al. 2005; Gudmundsdottir and Ashworth 2006; Moynahan and Jasin 2010). These phenotypes are also characteristic features of BRCA1-deficient cells, except that they exhibit a deficit in DSB repair by SSA (Scully and Livingston 2000; Venkitaraman 2002; Cousineau et al. 2005; Gudmundsdottir and Ashworth 2006; Moynahan and Jasin 2010).

These findings indicate that EMSY-overexpressing MCF-7 cells only partially mimic BRCA-deficient tumor cells. They exhibit both an enhanced rate of SCRS and decreased efficiency of HR repair of I-SceI-induced DSBs, but show a decreased rate of spontaneous HR and normal efficiency of DSB repair by SSA, suggesting that increased EMSY level interferes with the recruitment/activation of ATR without affecting that of ATM or the processing of DSB ends into ssDNA by BRCA1/MRN or the ability of BRCA2/RAD51 to bind/stabilize ssDNA. We extensively discuss the molecular details of how this can happen, to appreciate all phenotypes of BRCA deficiency as markers of deregulated HR orchestrating at least S/G2/M-transition checkpoints and gene mutation-avoidance systems.

\section{Materials and methods}

DNA manipulations, cell lines, culture, and DNA transfections

Three distinct recombination/repair reporter MCF-7 cell lines were transfected with pcDNA3.1Neo-based expression vector, with or without short EMSY (1-478) (HughesDavies et al. 2003), using FuGENE 6 transfection reagent (Boehringer-Mannheim, Indianapolis, IN). Forty-eight hours later, the transfected cells were cultured in medium containing G418 (600 $\mu \mathrm{g} / \mathrm{mL})$. Independent $\mathrm{G} 418^{\mathrm{R}}$ cell clones were picked and amplified individually to analyze short EMSY integration and its expression by PCR, RTPCR and Western blotting.

\section{PCR}

Genomic DNA was extracted from individual cell clones, and $400 \mathrm{ng}$ subjected to PCR with the following primer pair: EMSY37-F (5'-agggatgaatgcaaaagaat- $\left.3^{\prime}\right)$ and pcDNA3.1Neo-R (5'-tctgagatgagttttgttc- $\left.3^{\prime}\right)$, which specifically amplifies a fragment of 1,397 bp from exogenous EMSY but not endogenous EMSY.

\section{RT-PCR}

RNA was extracted from individual cell clones with Trizol reagent and transcribed to cDNA with reverse transcriptase and primers (hexamers) from the SuperScript First-Strand Synthesis System RT-PCR kit (Invitrogen, Carlsbad, CA). The same primer pair described for PCR was employed to amplify exogenous EMSY cDNA. In the same reaction tube, EMSY1810-R (5'-tttctcctccagcatttag-3') was added to amplify, together with $E M S Y 37-\mathrm{F}$, a 1,773-bp fragment from endogenous wild-type (wt) $E M S Y$. In reaction controls, the primer pair $18 \mathrm{~s}-\mathrm{F}\left(5^{\prime}\right.$-tgaggccatgattaagaggg- $\left.3^{\prime}\right)$ and $18 \mathrm{~s}-\mathrm{R}$ (5'-cgctgagccagttcagt gtag- $\left.3^{\prime}\right)$ amplified a 642-bp fragment of ribosomal RNA. Puro ${ }^{\mathrm{R}}, \mathrm{Hyg}^{\mathrm{R}}$, and BRCA2 expression was assessed with Puro-F (5'-cgaccttccatgaccgagta- $\left.3^{\prime}\right)$ and Puro-R ( $5^{\prime}$-gccttccatctgttgctg- $\left.3^{\prime}\right)$, Hyg-F (5'-cggcgagtacttct acacagc- $\left.3^{\prime}\right)$ and Hyg-R (5'-ttcgaacacgcagatgcagtcg- $\left.3^{\prime}\right)$, BRCA2-F $\quad\left(5^{\prime}\right.$-ccaagtcatgccacacattc- $\left.3^{\prime}\right)$ and BRCA2-R ( $5^{\prime}$-ttgaccaggtgcggtaaaat- $\left.3^{\prime}\right)$. In addition, $R A D 51$ expression was analyzed with the primer pair $R A D 51-\mathrm{F}\left(5^{\prime}\right.$-gagtaatg gcaatgcagatgca- $\left.3^{\prime}\right)$ and RAD51-R (5'tcgacccgagtagtctgt tct- $\left.3^{\prime}\right)$. PCR amplifications were undertaken with the Expand High Fidelity PCR System kit (Boehringer-Mannheim).

\section{Protein manipulations}

Proteins were extracted and quantified as described previously (Abaji et al. 2005). Fifty micrograms of protein extract was separated on $8 \%$ sodium dodecyl sulfatepolyacrylamide gel, transferred to nitrocellulose membranes (Amersham, Piscataway, NJ) and probed with crude rabbit antisera $(1 / 3,000)$ directed against EMSY. For RAD51 detection, $50 \mu \mathrm{g}$ of protein extracts was separated on $12.5 \%$ gel and probed with mouse anti-RAD51 antibody (51RAD01, Calbiochem, La Jolla, CA) with actin as loading control (ACTN05, Medicorp, Montreal, QC, Canada).

\section{HR frequency and rate}

HR rate and frequency were determined from at least two to three independent experiments, respectively, as described previously (Lemelin et al. 2005). Briefly, in each experiment and for each cell line, 12 independent cultures (1-100 cells) were plated in parallel and cultured to confluence. Cells were trypsinized, counted, and a portion was taken for plating efficiency estimation. $5 \times 10^{5}$ cells were plated $24 \mathrm{~h}$ before adding Puro at $1.0 \mu \mathrm{g} / \mathrm{mL}$. Since HR between direct repeats can delete $H y g^{R}$ during culture, direct-repeat cell lines were maintained without hygromycin before Puro 
selection. The number of Puro ${ }^{\mathrm{R}}$ colonies divided by the number of plated cells determined HR frequency. The HR rate was calculated from these frequencies by the fluctuation test.

For I-SceI-induced HR experiments, the vectors $\mathrm{p} \beta$ actinSceI and pFRED25, which express the meganuclease I-SceI and green fluorescent protein (GFP), respectively, were co-transfected into $2 \times 10^{5}$ cells with FuGENE 6. In parallel experiments, the same number of cells was transfected with pFRED25 and pMC1Neo, the latter to correct for DNA content as a control for I-SceI efficiency. GFPexpressing cells were counted $48 \mathrm{~h}$ after transfection to examine the efficiency of transfection and normalize HR frequencies. Puro selection was performed 10 days after transfection. The frequency of I-SceI-induced HR was calculated by dividing the number of Puro $^{\mathrm{R}}$ colonies transfected with I-SceI by the number of Puro $^{\mathrm{R}}$ colonies transfected with control DNA and normalized for transfection efficiency.

\section{Statistical analysis}

HR frequencies and rates were assessed by one-way ANOVA. For the analysis of recombination/repair pathways, contingency tables were used with the Chi-square test.

\section{Results}

\section{Experimental strategy}

The MCF-7 cell lines employed as backgrounds for EMSY overexpression each carries a single, intact copy of a recombination/repair construct containing either a directrepeat or an inverted-repeat of two inactive Puro $^{\mathrm{R}}$ genes separated by the $\mathrm{Hyg}^{\mathrm{R}}$ gene (Fig. 1; Lemelin et al. 2005). Deleting EagI and BssHII restriction sites and inserting one I-SceI cleavage site inactivated the full-length Puro gene, whereas the wt Puro gene contained an inactivating $5^{\prime}$ deletion, including the promoter. A recombination/repair event between the two Puro cassettes would reconstitute a functional Puro $^{\mathrm{R}}$ gene through loss of I-SceI and gain of wt EagI/BssHII sites, restoring resistance to the drug puromycin in colony assay.

In this type of assay system (Moynahan and Jasin 2010), the efficiency of recombination/repair also depends on the ability of a cell to at least survive the damage and express the reporter gene. It has been consistently demonstrated with various organisms that when more than two copies of a reporter gene lie adjacent to one another, the tandem can undergo chromatin assembly and transcription repression, an epigenetic phenomenon known as homology- or repeatinduced gene silencing (HIGS or RIGS) that resembles
A Inverted repeat

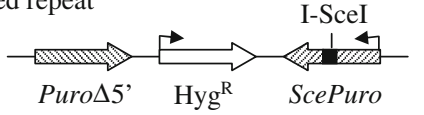

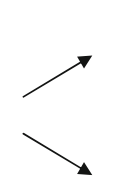
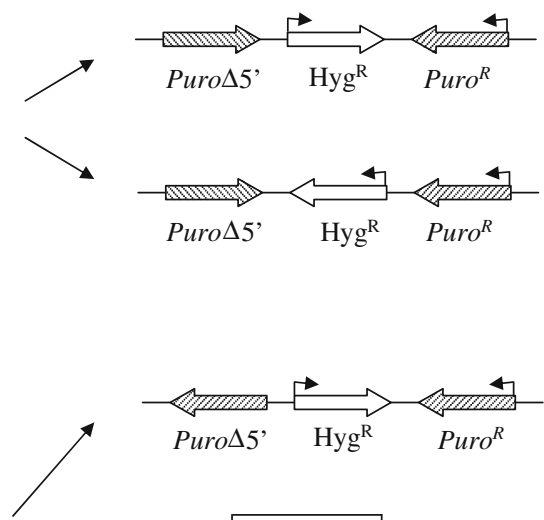

B Direct repeat
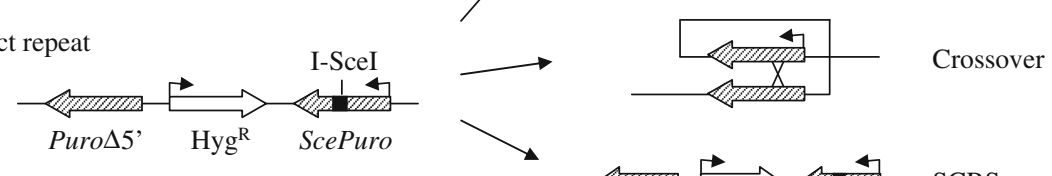
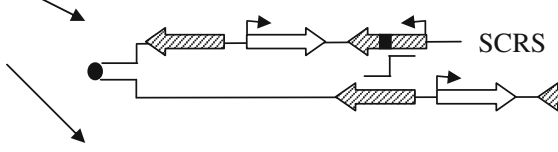

Gene Conversion

Crossover (Inversion)

Gene Conversion
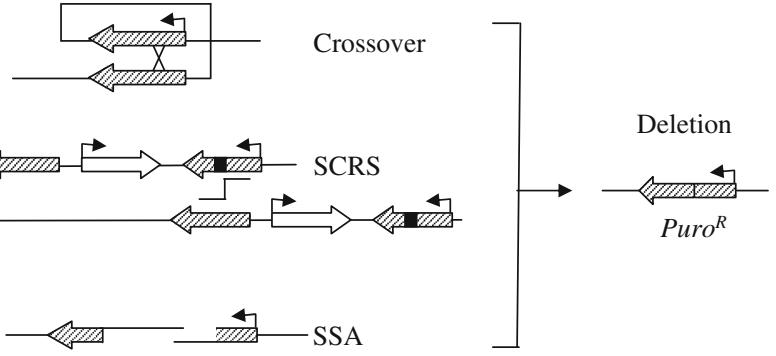

Fig. 1 Homologous recombination (HR) between direct and inverted repeats. HR reconstitutes a functional Puro $^{\mathrm{R}}$ gene through loss of the I-SceI site and gain of $E a g I / B s s H I I$ sites. Since I-SceI insertion mutation in ScePuro entails the deletion of EagI and BssHII sites, only error-free HR repair events between the two Puro $^{\mathrm{R}}$ cassettes can restore a functional Puro gene. Gene conversion restores one functional Puro gene without affecting the overall structure of the locus, whereas crossover associated or not with gene conversion inverts $H y g^{\mathrm{R}}$ gene between inverted Puro repeats (a) or deletes $\mathrm{Hyg}^{\mathrm{R}}$ between direct Puro repeats $(\mathbf{b})$. Deletion events can also result from SCRS or SSA (see text) 
position-effect variegation, in which chromatin assembly can spread into adjacent domains (Henikoff 1998). The use of single-copy MCF-7 cell clones would thus prevent repression of Puro $^{\mathrm{R}}$ gene by HIGS. In addition, the Puro $^{\mathrm{R}}$ gene was also designed to escape repression from the adjacent marker $\mathrm{Hyg}^{\mathrm{R}}$ gene (Lemelin et al. 2005). It has also been consistently shown in various organisms that in such cell clones, which had initially been selected for the expression of a marker gene, the adjacent reporter gene was usually repressed (Villemure et al. 2001; Eszterhas et al. 2002). Such an HIGS-independent, gene-silencing phenomenon, termed 'transcriptional interference' and 'promoter suppression', can occur whether adjacent transcription units are arranged in direct or inverted orientations. Transcriptional interference/suppression is cis-acting, epigenetic and heritable. Since EMSY interacts with CAFs and its increased level represses the transcription of reporter genes (Hughes-Davies et al. 2003), a transcription interference/suppression-free assay system was considered necessary for this study.

Nevertheless, we investigated the effect of increased EMSY level on the expression of $\mathrm{Hyg}^{\mathrm{R}}$ and Puro $^{\mathrm{R}}$ genes at distinct loci. $H y g^{\mathrm{R}}$ expression is driven by the Herpes simplex virus thymidine kinase $(T K)$ gene promoter, whereas that of Puro $^{\mathrm{R}}$ is under control of the strong cellular-housekeeping phosphoglycerate kinase gene promoter
(Lemelin et al. 2005). MCF-7 cells exhibit normal EMSY copy number and expression level, whereas overexpression of a truncated $E M S Y$ form, containing the binding sites of BRCA2, HP1 $\beta$ and BS69, represses both $\mathrm{BRCA}_{2} 2_{\mathrm{ex}}{ }^{-}$ transactivation potential and expression of a $T K$ gene promoter in transient assays (Hughes-Davies et al. 2003). To examine this in stable MCF-7 cell clones, the three distinct reporter cell lines dA9, iA12 and iA7, grown in Hyg-free medium, were transfected with pcDNA3.1Neo containing or not short EMSY (Hughes-Davies et al. 2003). Since DNA transfection per se can activate DDR (Igoucheva et al. 2006) and DDR activation can repress both p53-dependent and -independent gene expression (Zhou et al. 2007), and p53 can repress all viral promoters driving the expression of reporter genes (Lemelin et al. 2005), independent $\mathrm{NeO}^{\mathrm{R}}$ cell clones were picked, amplified and only then analyzed by PCR of genomic DNA, RT-PCR and Western blotting. Direct-repeat (dA9) and inverted-repeat (iA12 and iA7) cell lines presented similar expression levels of either endogenous or exogenous EMSY (Fig. 2). However, the slight increase in EMSY protein level did not repress $\mathrm{Hyg}^{\mathrm{R}}$, since individual $\mathrm{Neo}^{\mathrm{R}}$ cell clones, grown in parallel in G418- and Hyg-containing media, showed similar plating efficiency. In addition, no apparent change in Hyg or Puro expression was noted at the RNA level (data not included).
Fig. 2 Short $E M S Y$ expression in MCF-7 cell lines. PCR of genomic DNA was performed to demonstrate EMSY transgene integration. The primer pair employed amplifies only the EMSY transgene. Its mRNA was analyzed by qualitative RT-PCR with the same primer pair. As a control, a fragment from endogenous full-length $E M S Y$ was amplified in the same reaction. 18S rRNA was amplified as a control for RT-PCR. Water or no reverse transcriptase served as a negative control, whereas $E M S Y$-expressing vector DNA was used as a positive control. EMSY proteins were assessed by Western blotting. All the different EMSY cell lines examined are independent cell clones

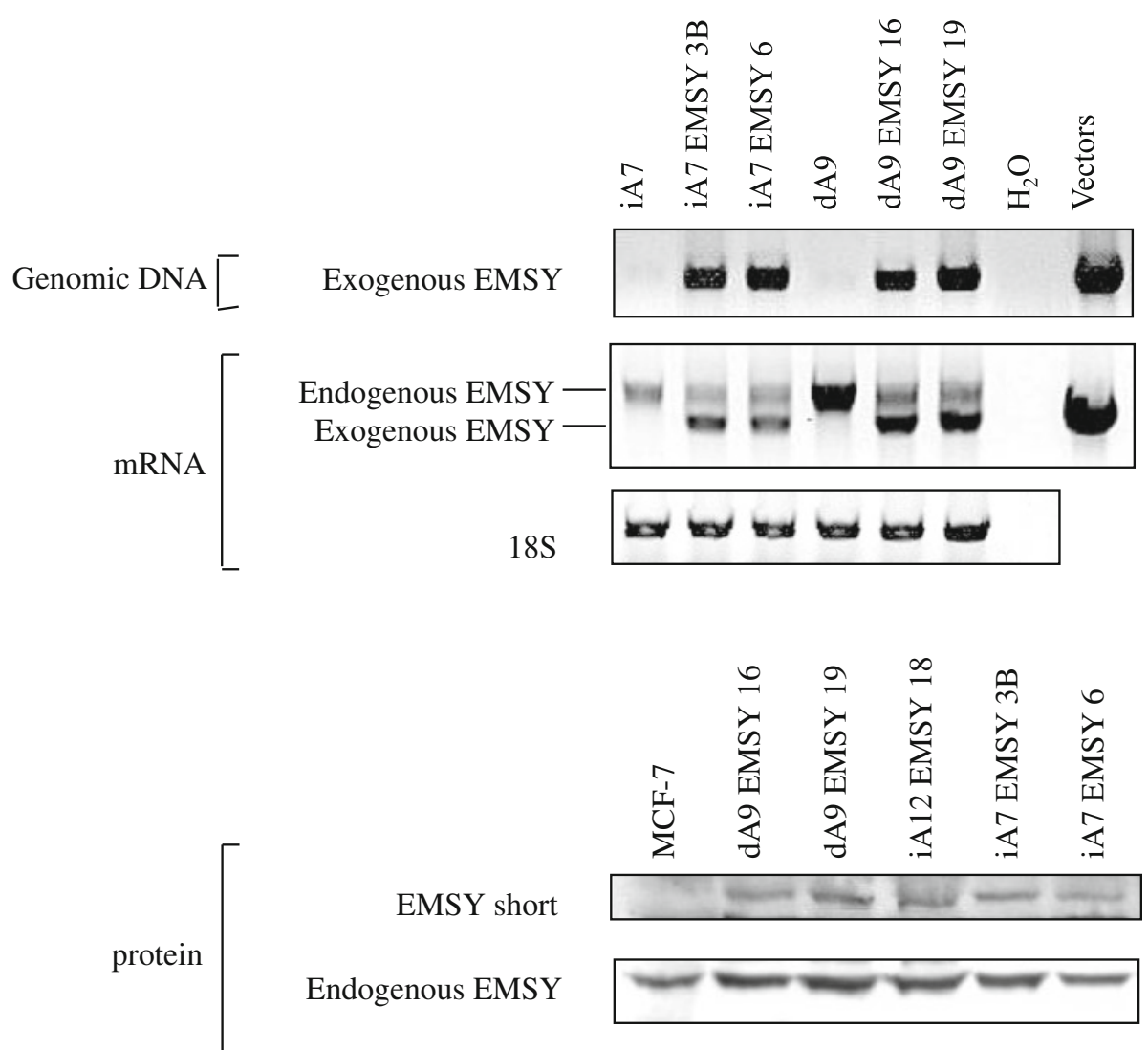


Short EMSY represses spontaneous

RAD51-mediated HR

One can envisage at least four more mechanisms by which short EMSY may affect spontaneous HR (i.e., without exposure to exogenous DNA-damaging agents). First, it may override PALB2 and thereby target BRCA2 for degradation in a manner similar to PALB2 depletion (Xia et al. 2006). Second, it may induce a BRCA2 conformational change that may affect its ability to interact and/or co-localize with RAD51, DSS1, or FANC-D2 at sites of DNA damage (Gudmundsdottir and Ashworth 2006). These proteins interact with the BRCA2 C-terminal domain, and deletion of such a domain or disruption of its interacting proteins has been shown to mimic BRCA2 deficiency, as revealed by decreased efficiency of HR repair of I-SceI-induced DSBs and hypersensitivity to PARP1 inhibitors and DSB-inducing agents (Gudmundsdottir and Ashworth 2006; Moynahan and Jasin 2010). In addition, deletion of the human BRCA2 C-terminal domain also increases the rate of spontaneous HR (Abaji et al. 2005). Thus, in either scenario, EMSY-overexpressing cell lines would exhibit all these phenotypes, as BRCA2-deficient CAPAN-1 cells do (Abaji et al. 2005).

Third, short EMSY may directly repress the expression of $R A D 51$ gene or its transactivator PTEN, since cells depleted of PTEN also undergo SC-type abnormalities similar to RAD51-deficient cells (Shen et al. 2007), BRCA2-deficient cells (Venkitaraman 2002) or short EMSY-expressing cells (Raouf et al. 2005). Fourth, it may override PALB2 and RPA, and thereby quench BRCA2 without affecting its stability. In these two scenarios, short EMSY-expressing cells would be expected to exhibit a hypo-recombination phenotype by decreasing the rate of spontaneous HR.

To examine which scenario is more likely, single Neo ${ }^{\mathrm{R}}$ / $\mathrm{Hyg}^{\mathrm{R}}$, inverted-repeat MCF-7 cell clones and EMSYoverexpressing derivatives were grown in parallel and subjected to Puro selection. In contrast to direct repeats, inverted repeats monitor exclusively RAD51-mediated HR: gene conversion and crossover (inversion) events (Fig. 1). EMSY-overexpressing MCF-7 cell lines displayed 4-16fold decreases in the rate of spontaneous HR, compared to their parental cell lines containing the empty vector (Table 1). In addition, no apparent difference in $R A D 51$ or $B R C A 2$ gene expression was noted between parental and derivative cell lines (Fig. 3). Since BRCA2 can bind only $20 \%$ of the cellular RAD51 pool (Marmorstein et al. 1998; $\mathrm{Yu}$ et al. 2003), these findings indicate that short EMSY repressed at least free RAD51 molecules.

Short EMSY heightens the rate of spontaneous SCRS

If short EMSY were to suppress spontaneous HR by interfering solely with free RAD51 molecules, one would
Table 1 Effect of EMSY on spontaneous inverted-repeat HR

\begin{tabular}{llrlr}
\hline Cell lines & Frequency $^{\mathrm{a}}$ & Ratio $^{\mathrm{b}}$ & Rate $^{\mathrm{c}}$ & Ratio $^{\mathrm{d}}$ \\
\hline iA7 & $2.05 \pm 0.7 \times 10^{-4}$ & & $4.94 \pm 0.7 \times 10^{-5}$ & \\
iA7/EMSY-3B & $3.25 \pm 1.6 \times 10^{-5}$ & 6.3 & $7.97 \pm 1.0 \times 10^{-6}$ & 6.2 \\
iA7/EMSY-6 & $2.86 \pm 1.4 \times 10^{-5}$ & 7.2 & $7.24 \pm 0.9 \times 10^{-6}$ & 6.8 \\
iA7/EMSY-9 & $5.61 \pm 2.9 \times 10^{-5}$ & 3.7 & $1.14 \pm 0.4 \times 10^{-5}$ & 4.3 \\
iA7/EMSY-31 & $1.30 \pm 0.5 \times 10^{-5}$ & 15.8 & $3.33 \pm 0.8 \times 10^{-6}$ & 14.8 \\
iA12 & $2.24 \pm 1.0 \times 10^{-3}$ & & $3.25 \pm 1.0 \times 10^{-4}$ & \\
iA12/EMSY-13 & $2.76 \pm 1.1 \times 10^{-4}$ & 8.1 & $4.83 \pm 1.2 \times 10^{-5}$ & 6.7 \\
iA12/EMSY-18 & $9.73 \pm 2.3 \times 10^{-5}$ & 23.0 & $2.03 \pm 0.6 \times 10^{-5}$ & 16.0 \\
\hline
\end{tabular}

${ }^{a}$ Frequency is determined as the number of Puro $^{\mathrm{R}}$ cell clones relative to the total number of viable cells before selection

${ }^{b}$ Ratio (parent/EMSY-expressing derivative cell lines) indicates recombination fold decrease in EMSY-expressing cells relative to their parents $(p<0.0001)$

${ }^{c}$ Rate represents the number of recombination events/locus/cell/generation

${ }^{\mathrm{d}}$ Ratio (parent/EMSY-expressing derivative cell lines) (iA7, $p=0.0003$; iA $12, p=0.0236$ )

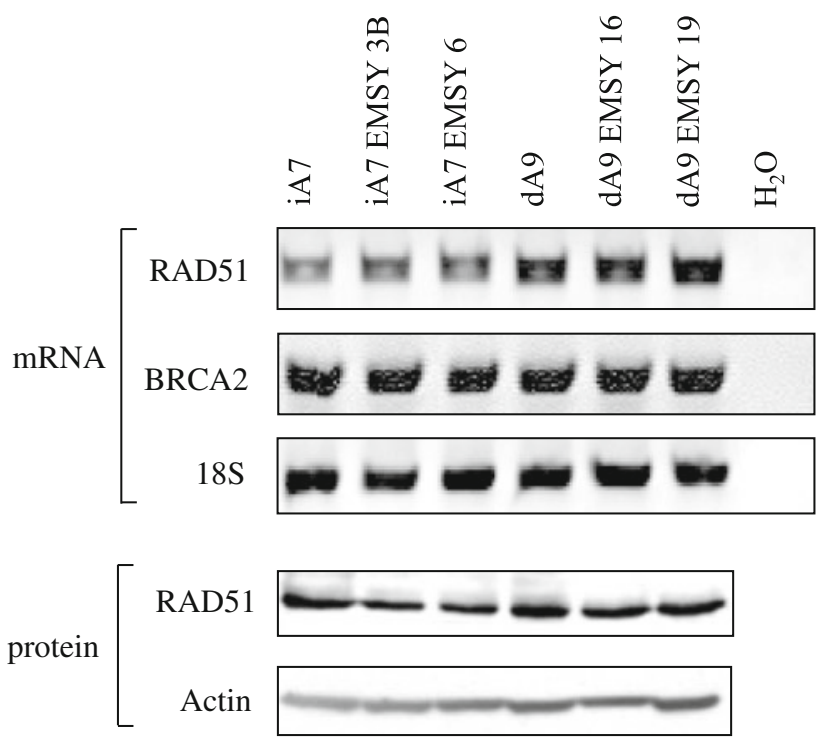

Fig. 3 Effect of short EMSY on $B R C A 2$ and $R A D 51$ expression. RTPCR reveals no apparent effect of short EMSY on RAD51 or BRCA2 expression levels. 18S rRNA was amplified as a control for RT-PCR. Water or no reverse transcriptase was a negative control. Western blotting analysis indicates no apparent effect of short EMSY on RAD51 protein level. Actin served as loading control

expect no effect on SCRS, since the process is RAD51independent and yet down-regulated by both BRCA1 and BRCA2 (Abaji et al. 2005; Cousineau et al. 2005). To examine this, we tested direct-repeat cell lines that monitor a mixture of HR and SCRS (Fig. 1). However, short EMSY did not affect the rate of Puro $^{\mathrm{R}}$ colony formation with direct repeats, but significantly shifted gene conversion to deletion events (Table 2), as revealed by PCR analysis of the recombinants (Abaji et al. 2005). The increase in deletion cannot be attributed to augmented crossover, since 
Table 2 Effect of EMSY on spontaneous direct-repeat HR

\begin{tabular}{|c|c|c|c|c|c|c|}
\hline Cell lines & Frequency & Ratio & Rate & Ratio & $\mathrm{GC}(\%)$ & SCRS $(\%)$ \\
\hline dA9 & $2.99 \pm 0.8 \times 10^{-6}$ & & $6.56 \pm 0.9 \times 10^{-7}$ & & $34 / 36(94)$ & $2 / 36(6)$ \\
\hline dA9/EMSY-7 & $2.30 \pm 0.9 \times 10^{-6}$ & 1.3 & $5.31 \pm 0.8 \times 10^{-7}$ & 1.2 & $12 / 14(86)$ & 2/14 (14) \\
\hline dA9/EMSY-9 & $2.32 \pm 0.7 \times 10^{-6}$ & 1.3 & $5.35 \pm 0.9 \times 10^{-7}$ & 1.2 & 9/11 (82) & 2/11 (18) \\
\hline dA9/EMSY-16 & $2.87 \pm 0.7 \times 10^{-6}$ & 1.0 & $5.72 \pm 0.7 \times 10^{-7}$ & 1.1 & $25 / 33(76)$ & $8 / 33(24)$ \\
\hline dA9/EMSY-19 & $2.55 \pm 1.0 \times 10^{-6}$ & 1.2 & $5.84 \pm 0.7 \times 10^{-7}$ & 1.1 & $56 / 92(61)$ & $36 / 92(39)$ \\
\hline dA9/EMSY-20 & $3.17 \pm 1.4 \times 10^{-6}$ & 0.9 & $6.84 \pm 1.0 \times 10^{-7}$ & 1.0 & $23 / 30(77)$ & $7 / 30(23)$ \\
\hline
\end{tabular}

Frequencies, rates and ratios were determined as described in Table 1

GC gene conversion

The apparent absence of EMSY effect on the frequency $(p=0.93)$ and rate $(p=0.43)$ of spontaneous Puro ${ }^{\mathrm{R}}$ colony formation appears to be due to a decrease in RAD51-mediated GC events compensated by an increase in RAD51-independent SCRS events $(p=0.004)$

short EMSY represses such HR events at inverted repeats (Table 1). In addition, neither BRCA2 nor BRCA1 represses crossover in favour of gene conversion as the RAD51-interacting BLM or WRN helicase does with HR intermediates containing crossed DNA strands: Holliday junctions (HJs) (Abaji et al. 2005; Cousineau et al. 2005). Collectively, these findings indicate that short EMSY not only interferes with free RAD51 molecules and BRCA2/ RAD51 complexes, but also disrupts SCC/alignment.

\section{Short EMSY represses BRCA2/RAD51-mediated HR repair of DSBs}

To examine this, direct-repeat MCF-7 cell lines and EMSY-overexpressing derivatives were transiently cotransfected in parallel with the $\mathrm{p} \beta$ actin/I-SceI vector, which expresses I-SceI, and a GFP-expressing vector, employed to evaluate transfection efficiency. No apparent difference in cell viability was noted after transfection between the parental cell line and $E M S Y$-overexpressing derivatives (data not included). When the Puro gene is cleaved at the I-SceI site, HR repairs the DSB (Moynahan and Jasin 2010). I-SceI expression increases the frequency of Puro ${ }^{R}$ colony formation with all cell lines, whereas EMSYoverexpressing derivatives consistently present threefold fewer colonies than their parents do (Table 3).

HR repair of I-SceI-induced DSBs between direct repeats occurs almost exclusively by gene conversion with few deletion events attributed to SSA (Cousineau and Belmaaza 2007; Moynahan and Jasin 2010). SSA, which obligatorily leads to deletion between direct repeats, cannot be monitored with inverted repeats, since the processing of DSB ends by BRCA1/MRN and ATM would generate identical rather than complementary ssDNA ends that would anneal (Fig. 1). Consistent with BRCA2/RAD51 complexes acting downstream of BRCA1/MRN (Greenberg et al. 2006; Zhang et al. 2009; Moynahan and Jasin 2010), the efficiency of DSB repair by SSA decreases in BRCA1-deficient cells
Table 3 Effect of EMSY on I-SceI-induced HR

\begin{tabular}{lrlll}
\hline Cell lines & Frequency $^{\mathrm{a}}$ & Ratio $^{\mathrm{b}}$ & GC (\%) & SSA (\%) \\
\hline dA9 & $217.63 \pm 67.6$ & & $68 / 74(92)$ & $6 / 74(8)$ \\
dA9/EMSY-7 & $81.32 \pm 40.3$ & 2.7 & $53 / 68(78)$ & $15 / 68(22)$ \\
dA9/EMSY-9 & $75.59 \pm 38.5$ & 2.9 & $66 / 90(73)$ & $24 / 90(27)$ \\
dA9/EMSY-16 & $70.21 \pm 21.3$ & 3.1 & $52 / 66(79)$ & $14 / 66(21)$ \\
dA9/EMSY-19 & $71.64 \pm 33.0$ & 3.0 & $55 / 78(71)$ & $23 / 78(29)$ \\
dA9/EMSY-20 & $82.45 \pm 37.2$ & 2.6 & $47 / 58(81)$ & $11 / 58(19)$ \\
\hline
\end{tabular}

$G C$ gene conversion, SSA single-strand annealing

${ }^{a}$ Frequency fold induction represents the mean of at least three independent experiments for each cell line $(p=0.0064)$

${ }^{\mathrm{b}}$ Ratio indicates recombination fold decrease in EMSY-expressing cells relative to their parents

${ }^{c}$ EMSY shifts the proportion of GC events to SSA $(p=0.029)$; the absolute value of SSA events remained unchanged but their proportion increased in comparison to the decreased number of GC events

and increases in RAD51- or BRCA2-deficient cells at the expense of reduced gene conversion (Daboussi et al. 2002; Abaji et al. 2005; Cousineau et al. 2005; Gudmundsdottir and Ashworth 2006). To determine whether short EMSY also affected DSB repair by SSA, we investigated the structure of I-SceI-induced recombinants by PCR (Abaji et al. 2005). Taking into consideration the threefold decrease in the overall frequency of I-SceI-induced HR, PCR analysis indicates that short EMSY lowers the efficiency of gene-conversion repair by 3.7-fold and shifts DSB repair from gene conversion to SSA, without affecting the efficiency of the latter (Table 3).

\section{Discussion}

Briefly, our findings indicate that an increased level of the EMSY N-terminal domain only partially mimics BRCA2 deficiency. Similar to BRCA2-deficient CAPAN-1 cells (Abaji et al. 2005), EMSY-overexpressing MCF-7 cells also 
exhibit an increased rate of SCRS and a deficit in HR repair of I-SceI-induced DSBs. However, unlike CAPAN-1 cells that present an increased rate of spontaneous HR and heightened efficiency of DSB repair by SSA (Abaji et al. 2005), EMSYoverexpressing MCF-7 cells rather display a decreased rate of the former and normal efficiency of the latter.

The differential effect of short EMSY on these processes, together with the lack of influence on expression of the reporter genes $H y g$ and Puro at three distinct loci and endogenous RAD51, BRCA2 and EMSY, seems to argue against EMSY as a general chromatin-assembly factor/ transcription repressor. The lack of effect on gene expression could not be attributed to the slight elevation of EMSY level in MCF-7 cell lines, as a higher level of a similar truncated form of EMSY in a telomerase-immortalized human breast epithelial cell line also does not affect BRCA2, BRCA1, p53 or $p 21$ expression (Raouf et al. 2005). In addition, it also does not much affect the stability of BRCA2 protein or its ability to interact and/or co-localize with RAD51, since this would confer hyper-recombination as BRCA2 deficiency does (Abaji et al. 2005). Rather, short EMSY bestows hypo-recombination by decreasing the rate of spontaneous HR, presumably by enhancing the repressive effect of BRCA2 on RAD51 (Abaji et al. 2005).

Both the promotion of RAD51 activity by BRCA2 in response to I-SceI-induced DSBs and its repression in the absence of such lethal damage were thought to be orchestrated by BRCA1, ATR and ATM (Abaji et al. 2005; Cousineau et al. 2005). Consistent with this view are the findings that, in undamaged human cells, the BRCA2 C-terminal RAD51-binding motif ser3291 encoded by exon27 (BRCA2 $2_{\text {ex } 27}$ ) is phosphorylated by CDK1, a posttranslational modification that blocks its interaction with RAD51 (Thorslund and West 2007). However, after the induction of DSBs that inactivate CDK1, BRCA 2 ex27 becomes de-phosphorylated, and its ability to both bind RAD51 and carry out HR repair of such lethal damage is restored (Thorslund and West 2007). RAD51 is functional as oligomers ( 1 oligomer contains 6 or 7 RAD51 monomers) that coat $3^{\prime}$-ssDNA and form a nucleoprotein filament that undertakes the DNA strand-exchange reaction by invading an intact homologous DNA (dsDNA) to prime new DNA synthesis and thus repair the damage (Thorslund and West 2007). Whereas the eight BRC repeats encoded by exon 11 (BRCA2 $2_{\text {ex } 11}$ ) can bind both RAD51 monomers and oligomers, $\mathrm{BRCA} 22_{\mathrm{ex} 27}$, which is unrelated to $\mathrm{BRC}$ repeats, exclusively binds RAD51 oligomers or RAD51 filament (Thorslund and West 2007). Since BRCA2 can bind only $20 \%$ of the cellular RAD51 pool (Marmorstein et al. 1998; Yu et al. 2003), one way by which short EMSY could repress both spontaneous HR and HR repair of DSBs is to both disrupt RAD51 oligomers into monomers and maintain $\mathrm{BRCA} 2_{\mathrm{ex} 27}$ phosphorylation.
EMSY-overexpressing MCF-7 cells exhibit approximately a fourfold decrease in the efficiency of HR repair of I-SceI-induced DSBs similar to BRCA1- or BRCA2-deficient tumor cells (Abaji et al. 2005; Cousineau et al. 2005), or hypoxic human cells, since hypoxia also decreases the synthesis of HR proteins to offset chemo- and radioresistances (Chan et al. 2008). Consistently, a similar decrease has also been reported with cells repressed or disrupted in BARD1 (Westermark et al. 2003); MRN (Yang et al. 2006); BRIP1 (BRCA1-interacting protein, also known as the helicase BACH1) (Litman et al. 2005); CtIP that links BRCA1 to MRN (Chen et al. 2008); ATM (Golding et al. 2004); ATR (Wang et al. 2004); CHK2 (Zhang et al. 2004); CHK1 (Sorensen et al. 2005); PALB2 (Xia et al. 2006); RPA (Sleeth et al. 2007); or RAD51 (Daboussi et al. 2002). Since short EMSY neither represses the expression of HR reporter genes nor affects SSA efficiency, the fourfold decrease in HR repair of I-SceI-induced DSBs cannot be ascribed to chromatin assembly diminishing DNA accessibility to transcription factors and restriction enzymes (Villemure et al. 2001). Rather, it could be due to either reduced efficiency of RAD51-mediated DNA strand-exchange/invasion or I-SceI-induced cell death (apoptosis) or permanent cell-cycle arrest (senescence), in which case the essential role of HR in cell survival would be at least checkpoint rather than DSB repair per se. Consistent with this view, (a) all these HR mutant cells are hypersensitive to DSB-inducing agents that activate p53-dependent or independent apoptosis/senescence; (b) after p53 disruption or repression, the efficiency of HR repair of I-SceIinduced DSBs increases by up to 20 -fold, whereas the rate of spontaneous HR remains unchanged in the absence of such lethal damage (Akyuz et al. 2002; Lemelin et al. 2005); and (c) similar to BRCA1, both BRCA2 and RAD51 bind $\mathrm{p} 53$, and BRCA2/RAD51 complex represses the expression of p53-responsive genes in transient assays (Marmorstein et al. 1998). In such assays, DNA transfection per se can activate DDR, specifically the ATR/ATM pathway (Igoucheva et al. 2006), and DDR activation can repress both p53-dependent and independent gene expression (Zhou et al. 2007), and p53 can repress not only cellular genes but also all viral promoters that drive the expression of HR/transcription-reporter genes (Lemelin et al. 2005). Thus, since the I-SceI assay system does not discriminate between checkpoint/repair and apoptosis/ senescence, short EMSY may affect all DDR aspects.

However, short EMSY does not seem to interfere with the localization of activated ATM, the processing of DSB ends into ssDNA by BRCA1/MRN or the stability of ssDNA ends. If it were to negatively affect any of these processes, one would have expected a similar decrease in the efficiency of DSB repair by SSA, which also requires all these HR proteins, except BRCA2/RAD51 complex that 
would shift DSB repair from SSA to gene conversion (Abaji et al. 2005; Gudmundsdottir and Ashworth 2006; Moynahan and Jasin 2010). Rather, short EMSY shifted DSB repair from gene conversion to SSA without affecting the efficiency of the latter. Thus, it seems that short EMSY interferes with free RAD51 molecules and the loading of RAD51 oligomers by BRCA2 $2_{\mathrm{ex} 27}$ at least at DSBs (Thorslund and West 2007), without affecting the ability of BRCA2/RAD51 to bind/stabilize ssDNA and promote SSA.

The SSA-promoting activity of BRCA2 has been appreciated with human full-length BRCA2 in CAPAN-1 cells (Abaji et al. 2005), and with its mini-homologs Brh2 in the smut, yeast-like fungus Ustilago maydis and CeBRC2 in C. elegans (Petalcorin et al. 2006; Mazloum et al. 2007). However, evidence indicates that in mammals, the SSA-promoting activity of BRCA2 may be overshadowed in the context of at least RPA/BRCA2/RAD51 complex and may become apparent only after the loss of either component of this complex. (a) In RAD51-disrupted cells that exhibit increased efficiency of SSA at I-SceIinduced DSBs (Daboussi et al. 2002), RPA/BRCA2 could still bind/stabilize ssDNA ends and promote SSA, given that similar to RPA and RAD51, BRCA2 also binds ssDNA, its C-terminal domain contains both ssDNA and dsDNA-binding motifs (Thorslund and West 2007). (b) Likewise, in BRCA2-disrupted cells that also display heightened efficiency of SSA at I-SceI-induced DSBs (Abaji et al. 2005; Gudmundsdottir and Ashworth 2006), RPA/RAD51 could still bind ssDNA ends and promote SSA. However, in this case, the ability of RAD51 alone to bind and displace RPA from ssDNA and form RAD51 filament to carry out DNA strand-exchange/invasion, as it does in vitro (Stauffer and Chazin 2004) and in CAPAN-1 cells causing hyper-recombination (Abaji et al. 2005), is crippled by I-SceI-induced DSBs (Abaji et al. 2005). In response to DSBs, ATM and its BRCA1-interacting tyrosine kinase c-ABL, another downstream target of DNAPK, as well as ATR proximal kinase CHK1, each phosphorylates RAD51 (Daboussi et al. 2002; Shiloh 2003; Sorensen et al. 2005).

It has been shown that RAD51 phosphorylation cripples the ability of RAD51 to both bind ssDNA and undertake DNA strand-exchange/invasion in vitro and HR repair of I-SceI-induced chromosomal DSBs, presumably by disrupting RAD51 oligomers into monomers and preventing RAD51 oligomerization (Yuan et al. 1998; Daboussi et al. 2002; Conilleau et al. 2004). Thus, in response to DSBs, RAD51 phosphorylation would affect not only its function but also that of BRCA2, since de-phosphorylated BRCA2 2 ex27 exclusively binds RAD51 oligomer but not RAD51 monomers (Thorslund and West 2007), raising the question: how does BRCA2/RAD51 complex conduct HR repair of DSBs? Since none of the models proposed for HR in general or for BRCA1/2 function in particular considers such a conundrum, we propose that BRCA2 may have the ability to protect its RAD51 monomers bound by the BRC repeats (exon 11) against phosphorylation (Abaji et al. 2005) (Fig. 4a).

(c) In the absence of RPA, BRCA2/RAD51 could still bind/stabilize ssDNA and promote SSA. Consistently, in in vitro assays, the BRCA2 C-terminal domain, Brh2 or CeBRC2 can displace RPA from ssDNA, load RAD51 oligomer onto the dsDNA-ssDNA junction that mimics one processed DSB end, and promote SSA between RAD51 filament and its complementary ssDNA, provided as linear, circular or embedded in synthetic D-loops (Petalcorin et al. 2006; Mazloum et al. 2007; Thorslund and West 2007; Fig. 4b).

Since short EMSY does not seem to negatively affect the SSA-promoting activity of BRCA2/RAD51, it must have then interfered at least with the loading of RAD51 oligomer by BRCA2 (Thorslund and West 2007). However, the loading of RAD51 oligomer by BRCA2 at DSBs cannot occur before recruitment/activation of ATR, since BRCA $2_{\text {ex } 27}$ would be still phosphorylated by CDK1. Then, the supply of RAD51 oligomers for RAD51 filament formation could originate afterwards from the BRC repeats of RPA/BRCA2/RAD51, EMSY/BRCA2/RAD51 and PALB2/BRCA2/RAD51, with each complex providing eight non-phosphorylated RAD51 monomers and, thus, a total of three to four RAD51 oligomers. This may be sufficient for HR repair, given previous demonstrations that only one DSB end can invade the undamaged template and prime new DNA synthesis, whereas the other DSB end can capture the displaced, newly synthesized DNA strand through SSA (Fig. 4b) or NHEJ under certain circumstances, culminating in deletion, insertion, or amplification events (Belmaaza and Chartrand 1994; Villemure et al. 1997, 2003). Thus, by overriding at least RPA, short EMSY could block the recruitment/activation of ATR, not only at stalled forksincreasing the likelihood of their collapse into DSBs (Raouf et al. 2005) as BRCA2 deficiency does (Lomonosov et al. 2003) - but also at such DSBs without affecting the localization of ATM or the processing of DSBs into ssDNA ends by BRCA1/MRN. This would decrease SCC/alignment, induce RAD51 phosphorylation, and maintain $\mathrm{BRCA} 2_{\mathrm{ex} 27}$ phosphorylation, thereby increasing SCRS and repressing both spontaneous HR and HR repair of DSBs without affecting SSA, as found to be the case.

That EMSY/BRCA2, RPA/BRCA2 and PALB2/ BRCA2 complexes have independently been fractionated from undamaged human cells indicates that, similar to PALB2, EMSY and RPA are also partners and stabilizers of BRCA2 (Hughes-Davies et al. 2003; Wong et al. 2003; Xia et al. 2006). However, regardless of their proportions 


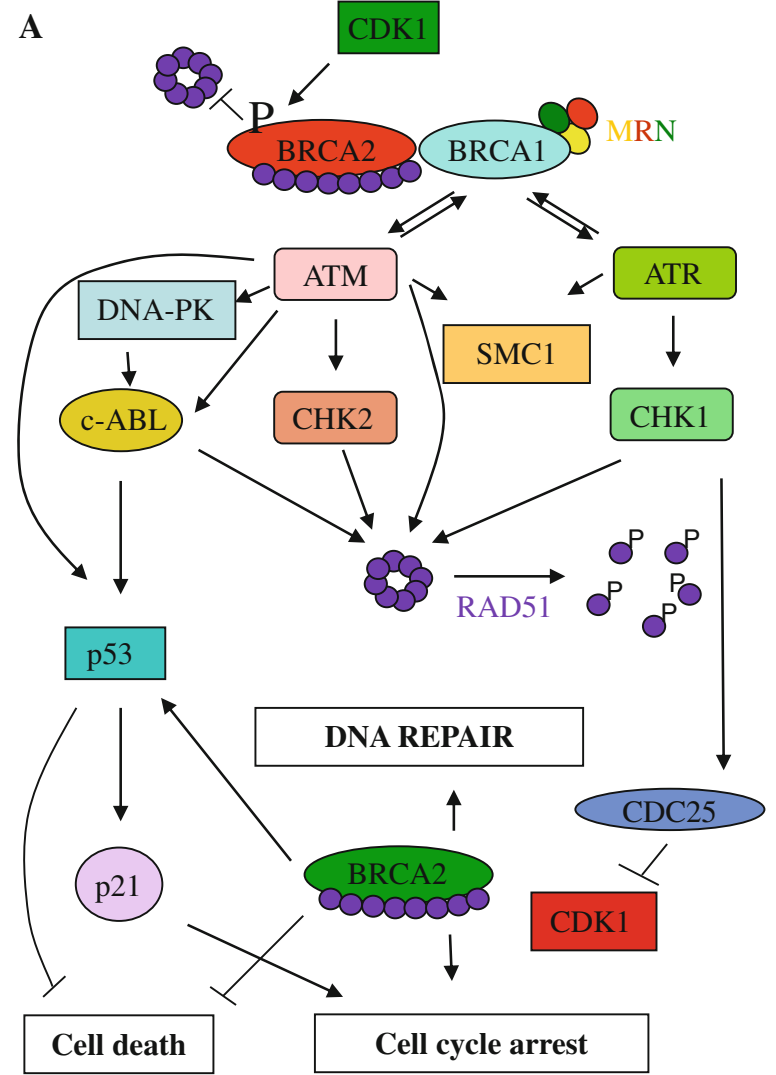

Fig. 4 A model for the BRCA2/RAD51 pathway in response to DSBs. Not all proteins and protein-protein interactions are shown and the outlines are for illustration only. a After their recruitment by BRCA1/MRN, BRCA2/RAD51 complexes act upstream and downstream of ATR (see text for details). b After disruption of nucleosomes and transformation of DSB ends into ssDNA by BRCA1/MRN and ATM (1), RPA/BRCA2/RAD51 recruits ATR (2) to enhance SCC/alignment before the formation/stabilization of D-loop at which the $3^{\prime}$-ssDNA end primes new DNA synthesis (3). ATR recruitment/activation could also occur during or after strand invasion and D-loop formation/stabilization, since transformation of DSB ends into $3^{\prime}$-ssDNA could be performed by the unwinding activity of MRN rather than its exonuclease activity that normally yields $5^{\prime}$-ssDNA ends. In this case, unwinding, strand invasion and D-loop formation/stabilization could occur simultaneously after the search for homology, alignment/pairing between DSB ends and the intact homologous dsDNA partner. In either case, the resulting intermediate can either disassemble, the newly synthesized strand can be displaced by unwinding to anneal with the non-invading $3^{\prime}$-ssDNA end to elicit non-crossover gene conversion only, or be processed to yield gene conversion with or without crossover (4). Short EMSY

in cells, increased EMSY level would be expected to shift protein concentration equilibrium towards EMSY/BRCA2, overriding PALB2 and RPA by quenching BRCA2 without affecting its overall stability. As it still interacts with HP1 $\beta$ and BS69, short EMSY might also override full-length EMSY. However, notwithstanding the exact role of fulllength EMSY, the effects of short EMSY reported here provide evidence that, in addition to chromatin and
B

1

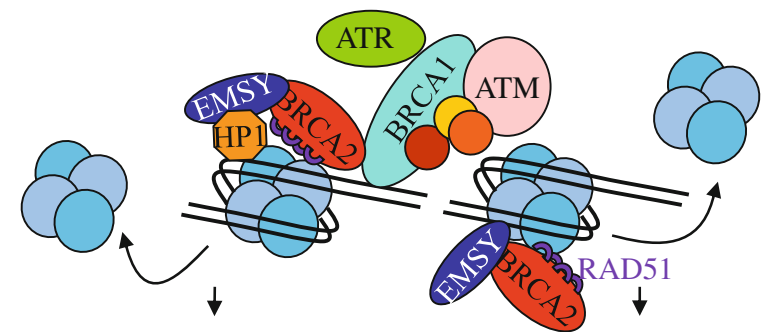

2

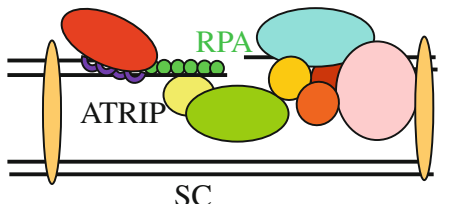

3
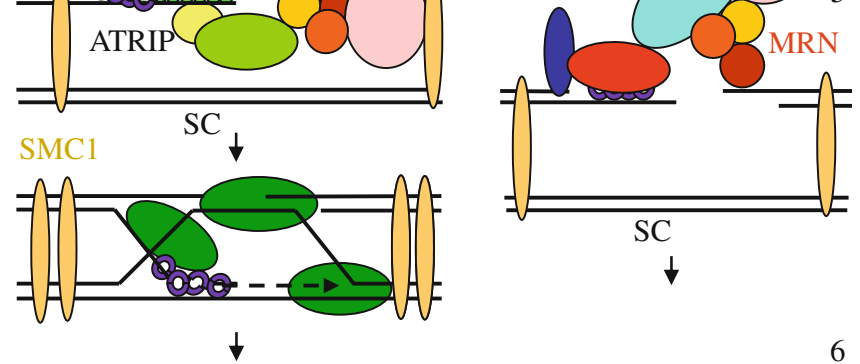

4

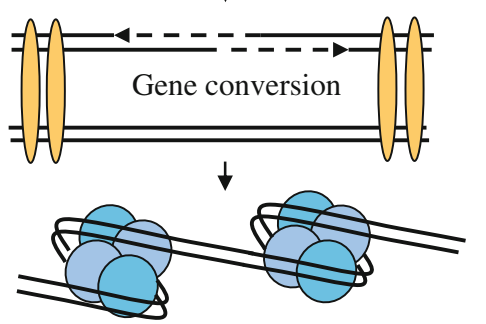

6

interferes with ATR recruitment/activation by overriding RPA (5), without affecting the ability of BRCA2/RAD51 to bind ssDNA and perform SSA (6). At D-loops, such as at gene promoters and replication origins, free RAD51 oligomers could also compete with RNA and DNA polymerases for ssDNA and thereby block initiation of transcription, replication and repair until activation/recruitment of PIKKs that would disrupt RAD51 oligomers into monomers. The loading of RAD51 oligomers by BRCA $2_{\text {ex } 27}$ on ssDNA may also act similarly until disruption of RAD51 filament by post-translational modifications (i.e., phosphorylation, ubiquitylation, sumoylation) that would allow transcription, replication and repair to proceed and thereby resume cell-cycle arrest. In this case, transcription and replication factors could act as cellular GPS (guiding position system) elements, recruiting checkpoint proteins to specific sites. Such BRCA2/RAD51 transcription/replication-checkpoint function could explain why checkpoint-deficient cells exhibit radio-resistant DNA synthesis, a characteristic feature of CIN syndromes, including BRCA-deficiency (see text). Thus, whereas RAD51 oligomer can act as a transcription/replication/repair repressor upstream of PIKKs, BRCA2/RAD51 complex can behave as both an activator and a repressor upstream and downstream of PIKKs, respectively

transcription regulation, $\mathrm{BRCA} 2_{\mathrm{ex} 3}$ may also be directly involved in the development of DDR in at least replication/ checkpoint and recombination/repair.

Such a heretofore unappreciated function of BRCA2 can be best examined in phenotypes of $B R C A 2$ knockout (KO) mice. Whereas BRCA2 null, BRCA2 $2^{\mathrm{eex} 1-5}$ and $B R C A 2^{\Delta \mathrm{ex} 11} \mathrm{KO}$ mice all die at an early embryonic stage in a manner similar to $R P A$ and $R A D 51 \mathrm{KO}$ mice, $B R C A 2^{\Delta \mathrm{ex} 27}$ 
KO mice are viable and develop normally (Donoho et al. 2003; Evers and Jonkers 2006; Friedberg and Meira 2006), indicating that whereas the function of at least BRCA 2 ex 3 and $\mathrm{BRCA} 2_{\mathrm{ex} 11}$ in replication/checkpoint is essential, that of BRCA2 $2_{\text {ex27 }}$ in RAD51-mediated HR repair of DSBs and resistance to DSB-induced lethality (Thorslund and West 2007; Moynahan and Jasin 2010) is dispensable for cell survival, proliferation and differentiation. The embryonic lethality of BRCA2 $\mathrm{KO}$ mice has been associated with chromosomal breakage and activation of p53, suggesting that: (a) such lethal damage does not arise accidentally in $B R C A 2^{\Delta \mathrm{ex} 27} \mathrm{KO}$ mice or normal proliferating/differentiating cells; and (b) the essential role of BRCA2 in replication/checkpoint is at least to prevent fork collapse into fatal injury rather than promote RAD51-mediated HR repair of collapsed forks.

Consistently, in response to fork stalling, bacteria, budding or fission yeast do not undergo fork collapse; only replication/checkpoint mutants do, through the activities of HR enzymes (Branzei and Foiani 2005). Such organisms do not possess BRCA homologs and yet they carry out DSB repair almost exclusively by $\mathrm{HR}$. In contrast, in organisms that possess BRCA homologs, NHEJ is the predominant DSB repair pathway, whether at collapsed forks or IR/ enzyme-induced DSBs. Therefore, in such evolved organisms, one would expect NHEJ and SSA to rescue HR mutants from DSB-induced lethality. In contrast, KO of HR genes, such as RPA, RAD51, BRCA1, BARD1, MRE11, RAD50, NBS1, ATR, CHK1, RAD51B, RAD51D, XRCC2, $T O P I I$, and $B L M$, in mice makes them all undergo chromosomal breakage and succumb to death in a manner similar to BRCA2 KO mice (Friedberg and Meira 2006). Thus, in addition to their well-established role in HR repair of DSBs, RAD51 and its paralogs RAD51B, RAD51D and XRCCs are also essential for checkpoint/fork stability. Consistent with this aspect, not all RAD proteins required for HR repair of DSBs are essential for survival; RAD52, $R A D 54$ and $R A D 51 \mathrm{C} \mathrm{KO}$ mice were all found to be viable (Friedberg and Meira 2006).

In addition, ATM, master of the response to DSBs including their repair by HR, NHEJ and SSA, is also dispensable for survival; KO mice remain viable, except that they exhibit hyper-sensitivity to IR, gonadotrophy, infertility, immunodeficiency and thymic lymphoma, since in germ-line cells and lymphocytes, DSBs rather arise in a programmed manner to initiate meiotic HR, ensuring "gene shuffling" and the orderly segregation of homologous chromosomes and thus the formation of healthy gametes, and V(D)J recombination (NHEJ) for immune system development, protecting against infectious diseases and cancer (Friedberg and Meira 2006). In the absence of ATM, such 'heavenly' breaks could trigger apoptosis/ senescence and act as anti-cancer barriers in 'specialized' tissues at the expense of their atrophy. Consistently, ATM/ $R A G 1$ and $A T M / R A G 2$ double $\mathrm{KO}$ (DKO) mice that no longer undergo programmed DSBs and V(D)J recombination also develop CIN and lymphoma (Petiniot et al. 2002). Moreover, other ATM downstream targets that play a role in $\mathrm{HR}$ repair of DSBs are also dispensable for survival; $C H K 2$ and $H 2 A X \mathrm{KO}$ mice are as viable as $A T M / C H K 2$ and $A T M / H 2 A X$ DKO mice (Friedberg and Meira 2006). Furthermore, NHEJ key components, including DNA-PK, another master of DSBs, Ku70, Ku80, Ku86 and Artemis, except ligase IV, are also dispensable for survival; KO mice remain viable (Friedberg and Meira 2006); and last but not least, genes of mutation-avoidance systems, such as base-excision repair/single-strand break repair (BER/ SSBR) of oxidative damage (XRCC1, APEX, LIG1, POL $\beta$, $F E N$, PARP1/PARP2), nucleotide-excision repair (NER) and transcription-coupled NER of DNA adducts (XPD, $X A B)$, or translesion DNA synthesis (TLS) (REV3), which are not necessary for DSB repair, all appear to be essential for survival (Friedberg and Meira 2006). Collectively, these findings indicate that (a) checkpoint/fork stability requires the participation of components of all DNAdamage repair mechanisms-HR, SSA, NHEJ, BER/ SSBR, NER and TLS_rather than DNA damage/repair per se; (b) the same machinery that responds to programmed DSBs also acts to suppress accidental breakage in both specialized and normal tissues; and (c) DSB has been conceived as a fundamental requirement of life, evolution and death, acting as a 'longevity clock' and 'quality control', eliminating aberrant proliferating/differentiating cells (cancer) and embryos (abortion).

In such replication/checkpoint mutants, the collapse of stalled forks into lethal DSBs has been associated with cleavage of HR intermediates (HJs) resembling a chickenfoot structure that forms as a consequence of "replicationfork reversal" (RFR) or "run-off" of specialized SC junctions resembling hemicatenanes (pseudo-double HJs) (Branzei and Foiani 2005; Fig. 5). In yeast, pseudo-double HJs have been shown to form during the early $\mathrm{S}$ phase, after origin firing, and to migrate, chasing the forks and presumably assisting SCC/alignment until anaphase whereas in human cells, such SC bridges have been reported to form at fragile sites, after replication stress, and at anaphase before their resolution by BLM/TOPIII $\alpha$ and TOPII and SC segregation as two intact chromosomes (Branzei and Foiani 2005, 2007; Chan et al. 2007, 2009). In yeast, pseudodouble HJs are thought to form at stalled forks by strand invasion and D-loop formation (template switch) as an error-free DNA-damage bypass mechanism compared to TLS polymerases, which often replicate across lesions in an error-prone manner (Branzei and Foiani 2007). Since BRCA $2^{\Delta \text { ex27 }}$ cannot carry out RAD51-mediated strand invasion (Thorslund and West 2007), 'hemicatenation' 


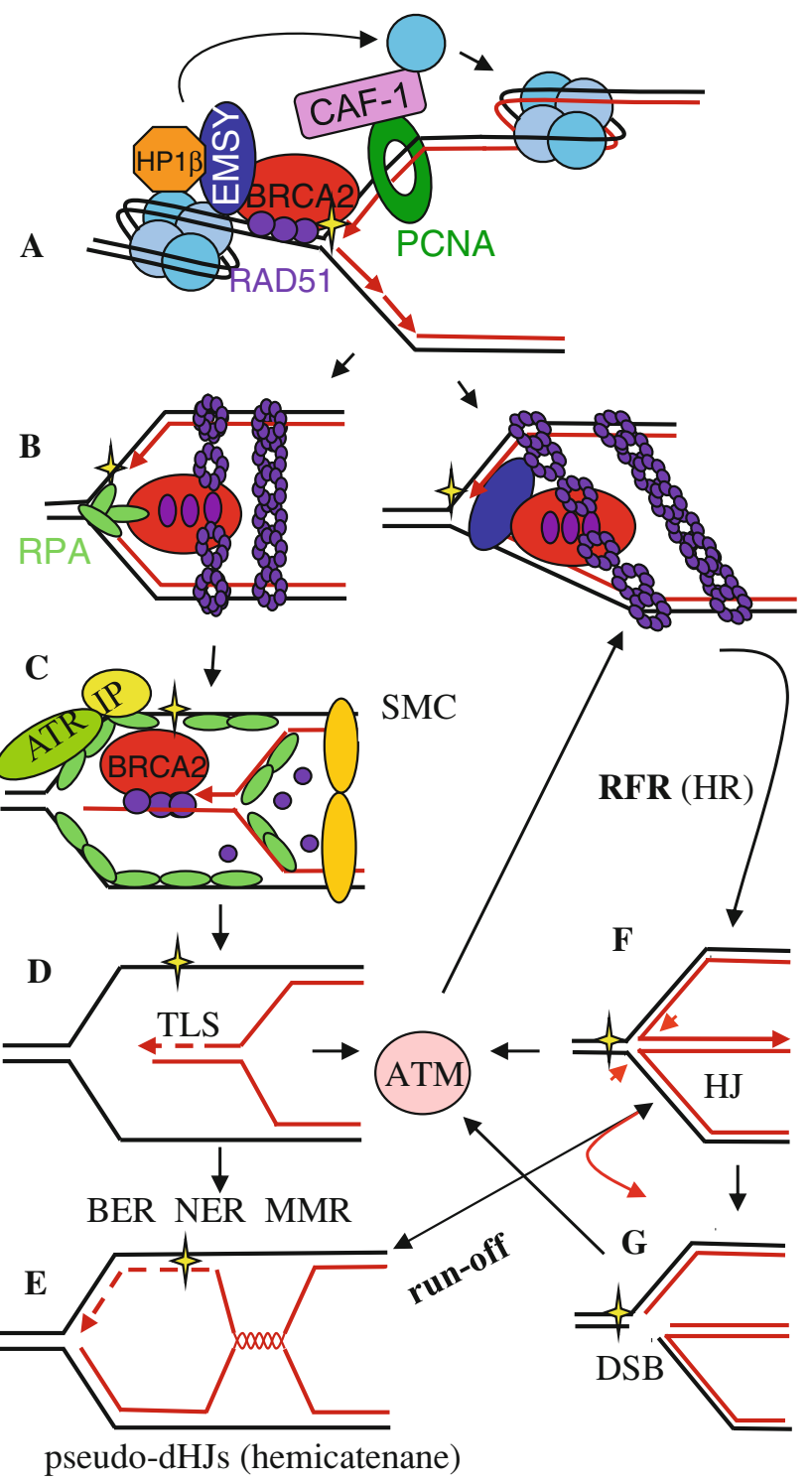

(HR) in mammals may result instead from BRCA2/RAD51mediated strand switching: twisting/melting dsDNA into ssDNA and, thus, displacement of both lagging and leading strands and their subsequent annealing into one harmless DSB end, flipping out the chicken foot, recruiting/activating ATR, ATM and DNA-PK to terminate HR within an intact chromosome (Fig. 5).

In support of this, (a) its mini-homologs Brh2 and CeBRC2 that each contains only one RAD51-binding BRC motif and one ssDNA-binding domain possess the ability to twist dsDNA into both D-loops and ssDNA and carry out SSA (Petalcorin et al. 2006; Mazloum et al. 2007; Fig. 4b). $\mathrm{BRCA} 2^{\Delta \mathrm{ex} 27}$ would be expected to conduct such reactions with higher efficiency, as it still possesses eight dsDNA- and ssDNA-binding motifs through its interaction with RAD51, given that RAD51 binds to ssDNA ( $5^{\prime}$ or $\left.3^{\prime}\right)$ and dsDNA with comparable affinities (Forget and Kowalczykowski 2010).
Fig. 5 A model for the BRCA2/RAD51 pathway in the response to stalled forks. After their recruitment by BRCA1/MRN, BRCA2/ RAD51 complexes may act in concert to (i) disassemble chromatin (A); (ii) maintain SCC/alignment $(B)$; (iii) effectuate strand-switching and thereby recruit/activate ATR to enhance SCC/alignment (C); (iv) provide one DSB end, and thereby activate ATM and DNA-PK $(D)$; and (v) twist the DSB end after its processing at least by error-free TLS polymerases into leading and lagging strands that would anneal back with the original templates, and thereby yield a hemicatenane $(E)$. If needed, the harmless DSB end ( $D$ and $F$ ) may engage in HR, NHEJ or SSA between neighbouring stalled forks during termination of the replication (S) phase (not shown). By interfering with ATR recruitment/activation, short EMSY could induce RFR (RAD51independent $\mathrm{HR}$ ) and chicken-foot formation $(F)$. HJ-resolving enzymes against crossover, such as BLM and WRN, may prevent fork collapse $(G)$ by competing with HJ-nicking enzymes (red arrows) at the expense of CIN. Unlike hyper-recombination, BRCA2/ RAD51-mediated strand switching at either stalled forks (hemicatenation/RFR) or DSBs does not require RAD51-filament formation, in which case the fourfold decrease in HR repair of I-SceI-induced DSBs by short EMSY could be attributed to apoptosis/senescence rather than decreased efficiency of strand switching. Consistently, meiotic HR does not require the loading of RAD51 oligomers by BRCA2 at programmed DSBs, since BRCA $2^{\Delta \operatorname{ex} 27} \mathrm{KO}$ mice are as fertile as wildtype animals, except that they exhibit hypersensitivity to IR, senescence and reduced life span. Thus, whereas BRCA2/RAD51mediated strand switching ensures survival, maintains chromosomal stability and acts as an anti-cancer barrier, SCRS and RAD51mediated strand exchange/invasion can compete with RFR for ssDNA and thereby decrease the likelihood of forks collapse at the expense of $\mathrm{CIN}$ and human diseases. Only abnormally proliferating cells crippled in an essential gene are prone to gene mutation/reversion and fork collapse

In addition, the binding of RAD51 oligomers to the homologous dsDNA partner inhibits DNA strand-exchange/ invasion in vitro and can be modulated by BRC repeats (Forget and Kowalczykowski 2010). In this case, BRCA2/ RAD51 complexes together with free RAD51 oligomers may also stabilize replication forks by holding SCs aligned, acting as bridges until activation of replication/checkpoint that would disrupt RAD51 oligomers into monomers and recruit bona fide cohesins (Fig. 5). (b) Mouse embryonic stem (ES) cells expressing BRCA2 $2^{\Delta \mathrm{ex} 27}$ exhibit heightened efficiency of SSA at I-SceI-induced DSBs and hyper-sensitivity to IR, but maintain both G1/S and G2/M checkpoints and resistance to UV radiation as wt ES cells (Morimatsu et al. 1998; Jasin 2002; Gudmundsdottir and Ashworth 2006), indicating that $\mathrm{BRCA} 2^{\Delta \mathrm{ex} 27}$ is still efficient in recruiting/activating at least ATR and DNA-damage repair by error-free TLS, NER, BER/SSBR, or mismatch repair (MMR) (Branzei and Foiani 2008). MMR key proteins are also components of BASC (Wang et al. 2000), and although dispensable for survival (Friedberg and Meira 2006), they have also been implicated in DDR and the processing of HR intermediates containing HJs or branched DNA in collaboration with NER proteins (Villemure et al. 2003). (c) NER, transcription-coupled NER and PCNA-dependent pathways of BER/SSBR also require BRCA1, BRCA2, RPA, RAD51 
and ATR (Le Page et al. 2000; Bogliolo et al. 2000; Daboussi et al. 2002; Aboussekhra and Al-Sharif 2005; Auclair et al. 2008). (d) As the localization of activated ATM and BRCA2/RAD51 complexes by BRCA1/MRN is needed for ATR activation in response to DSBs, that of ATR also seems to be required for ATM and DNA-PK activation in response to stalled forks (Stiff et al. 2006; Yajima et al. 2006). (e) BRCA1 and ATR have been shown to enforce TOPII-mediated decatenation G2 checkpoint (Deming et al. 2001). In normal proliferating cells, all replication forks would stall at termination of the $\mathrm{S}$ phase by catenanes, positive DNA supercoils that develop under torsional stress between advancing/colliding forks, acting as topological barriers, activating TOPII-mediated decatenation of SCs to allow completion of the $\mathrm{S}$ phase, chromosome condensation and segregation during the $\mathrm{G} 2$ and $\mathrm{M}$ phases (Deming et al. 2001; Branzei and Foiani 2008). Thus, with its HAT on doing the twist and changing partners at DNA, BRCA2 $2^{\Delta \mathrm{ex} 27}$ still has the ability to provide a finger to any stalled fork, and thereby act upstream and downstream of PIKKs, orchestrating at least S/G2/M-transition checkpoints and mutationavoidance systems as full-length BRCA2, ensuring the accuracy rather than efficiency of such DNA transactions that can be carried out in vitro and by organisms that do not possess BRCA homologs.

In addition, unlike humans, $B R C A 2^{\Delta \mathrm{ex} 27} \mathrm{KO}$ mice or mice heterozygous for BRCA2-truncating mutations are not spontaneously more cancer-prone than wt animals (Donoho et al. 2003; Evers and Jonkers 2006). Moreover, unlike BRCA2-deficient human cells (Abaji et al. 2005), mouse cells expressing BRCA $2^{\Delta e x 27}$ have not been reported to undergo hyper-recombination or SCRS (Gudmundsdottir and Ashworth 2006; Moynahan and Jasin 2010). These two 'mutator' phenotypes and cancer predisposition highlight the importance of both replication/checkpoint in chromosomal stability and the difference between human and mouse BRCA2. Whereas human BRCA2 contains one nuclear localization signal (NLS) at the C-terminal domain, mouse BRCA2 possesses an additional NLS at the $\mathrm{N}$-terminal domain (Jasin 2002). The majority of inherited, cancer-eliciting BRCA2 mutations encode truncated proteins as in CAPAN-1 cells, where BRCA2 is truncated at exon 11, weakly expressed, and exclusively localized in the cytoplasm, allowing both hyper-recombination and SCRS to take place (Abaji et al. 2005). Conversely, truncated mouse BRCA $2^{\Delta \operatorname{ex} 27}$ is expressed normally and localizes exclusively in the nucleus (Jasin 2002).

Hyper-recombination and its hallmarks are characteristic features of not only BRCA-deficient and BRCA-haploinsufficient tumor cells, but also normal breast epithelial cells and lymphocytes from healthy carriers of $B R C A$ mutations, indicating that a 'single hit' in a chromosomal stability gene is sufficient to deregulate HR and induce CIN and the emergence of pre-cancerous lesions (Cousineau and Belmaaza 2007). Although somatic BRCA mutations are scarce in sporadic breast cancer, representing less than $1 \%$, the remaining cases are either BRCA1- or BRCA2haploinsufficient due to loss (deletion/aneuploidy) or epigenetic silencing of wt BRCA alleles (Welcsh and King 2001), and all exhibit amplification of oncogenes most notably EMSY, MYC, E2F-1, CyclinD1, or AKT, or loss of tumor-suppressor genes, such as PTEN, p53, or $R B$ (Kenemans et al. 2004). Similar to EMSY, amplification/ overexpression of other oncogenes, such as MYC or E2F-1, has also been shown to induce fork stalling and CIN as well as fork collapse into DSBs, activating ATM and not ATR, triggering apoptosis/senescence, acting as an anti-cancer barrier (Hong et al. 2006; Halazonetis et al. 2008). Thus, oncogenes can behave as tumor suppressors. Similarly, aneuploidy also acts both oncogenically and as a tumor suppressor (Weaver et al. 2007).

Hyper-recombination and its hallmarks are also characteristic features of PARPI- and ATM-deficient cells or KO mice (Claybon et al. 2010) and cells disrupted in DNA-PK (Allen et al. 2002) or MMR proteins (Villemure et al. 2003), or cells expressing p53 mutant proteins (Daboussi et al. 2002; Akyuz et al. 2002; Lemelin et al. 2005) or derived from patients with CIN syndromes, such as ataxia telangiectasia, Bloom's syndrome, Werner's syndrome, and Fanconi's anemia, associated with mutations in ATM, BLM, WRN, and several FANC genes, respectively (Meyn 1997). Consistently, the most notable of $F A N C$ genes include FANC-D1 (BRCA2), FANC-D2, FANC-J (BRIP1, BACH1), and $F A N C$-N (PALB2) (Walsh and King 2007). In addition, similar to $B R C A 1$ and $B R C A 2$, the inheritance of a mutated copy of ATM, PALB2, BRIP1, p53 or CHK2 (mutated in Li-Fraumeni syndrome), MRE11 (mutated in ataxia telangiectasia-like disease), NBSl (mutated in Nijmegen breakage syndrome), or PTEN (mutated in Cowden disease) also confers a high lifetime risk of developing breast cancer (Walsh and King 2007). Cancer predisposition aside, patients with these syndromes also suffer from several other illnesses, such as neurological and cardiovascular diseases, diabetes, immunodeficiency, anemia, infertility, or premature aging as patients with Xeroderma pigmentosum, Cockyane syndrome, Trichothiodystrophy and RothmundThompson syndrome, associated with mutations in components of NER, transcription-coupled NER, and RecQ-like DNA helicases such as BLM and WRN (Shiloh 2003; Vogelstein and Kinzler 2004; Branzei and Foiani 2008).

In conclusion, we briefly wielded the 'triple-edged' sword of HR: life, death and human diseases. That BRCA1 and BRCA2 act upstream of PIKKs as the masters of chromosomal stability may also explain: (a) why among all the inherited, breast cancer-eliciting gene mutations identified to date, BRCA1 and BRCA2 represent the majority of cases, 
whereas ATM, CHK2, p53, MRE11, RAD50, PALB2, BRIP1 $(B A C H 1)$ and $P T E N$ each accounts for approximately $1 \%$ of the remaining cases (Walsh and King 2007); (b) why in sporadic breast cancer, the majority if not all cases are either BRCA1- or BRCA2-haploinsufficient (Welcsh and King 2001); and (c) why breast cancer exhibits decreased or increased levels of almost exclusively those proteins that interact with BRCA1 and BRCA2. This indicates that (a) cancer may be a gene-dosage disease, in which tumorsuppressor genes and oncogenes are two facets of the same process with dosage amount acting both as a cancer promoter and an anti-cancer barrier through fork stalling and collapse, respectively; and (b) tissue specificity of the tumor-suppressive or -promoting property of all these housekeeping chromosomal stability genes may be determined by tissuespecific DNA-damaging agents, such as estrogens, antiestrogens and phytoestrogens in breast cancer. The anticancer facet of such compounds could be enhanced if employed as tissue-specific carriers of potent DSB-inducing drugs.

Acknowledgments We are grateful to Dr. Luke Hughes-Davies (Cancer Research UK/Wellcome Trust Institute and the Departments of Pathology and Oncology, University of Cambridge, UK) for generously providing us with pcDNA-EMSY and EMSY antisera. We also thank Mr. Ovid Da Silva and the Research Support Office, CRCHUM, for his editorial assistance. This work was supported by the following grants: Canadian Institutes of Health Research/Canadian Breast Cancer Research Alliance (A. Belmaaza), and a Canderel fellowship and bursary from Faculté des études supérieures, Université de Montréal, and Institut du Cancer de Montréal (I. Cousineau).

Open Access This article is distributed under the terms of the Creative Commons Attribution Noncommercial License which permits any noncommercial use, distribution, and reproduction in any medium, provided the original author(s) and source are credited.

\section{References}

Abaji C, Cousineau I, Belmaaza A (2005) BRCA2 regulates homologous recombination in response to DNA damage: implications for genome stability and carcinogenesis. Cancer Res 65:4117-4125

Aboussekhra A, Al-Sharif IS (2005) Homologous recombination is involved in transcription-coupled repair of UV damage in Saccharomyces cerevisiae. EMBO J 24:1999-2010

Akyuz N, Boehden GS, Susse S, Rimek A, Preuss U, Scheidtmann $\mathrm{KH}$ et al (2002) DNA substrate dependence of p53-mediated regulation of double-strand break repair. Mol Cell Biol 22:6306-6317

Allen C, Kurimasa A, Brenneman MA, Chen DJ, Nickoloff JA (2002) DNA-dependent protein kinase suppresses double-strand breakinduced and spontaneous homologous recombination. Proc Natl Acad Sci USA 99:3758-3763

Auclair Y, Rouget R, Affarel B, Drobetsky EA (2008) ATR kinase is required for global genomic nucleotide excision repair exclusively during $\mathrm{S}$ phase in human cells. Proc Natl Acad Sci USA 105:17896-17901
Belmaaza A, Chartrand P (1994) One-sided invasion events in homologous recombination at double-strand breaks. Mutat Res 314:199-208

Bogliolo M, Taylor RM, Caldecott KW, Frosina G (2000) Reduced ligation during DNA base excision repair supported by BRCA2 mutant cells. Oncogene 19:5781-5787

Branzei D, Foiani M (2005) The DNA damage response during DNA replication. Curr Opin Cell Biol 17:568-575

Branzei D, Foiani M (2007) Interplay of replication checkpoints and repair proteins at stalled replication forks. DNA Repair (Amst) 6:994-1003

Branzei D, Foiani M (2008) Regulation of DNA repair throughout the cell cycle. Nat Rev Mol Cell Biol 9:297-308

Chan KL, North PS, Hickson ID (2007) BLM is required for faithful chromosome segregation and its localization defines a class of ultrafine anaphase bridges. EMBO J 26:3397-3409

Chan KL, Palmai-Pallag T, Ying S, Hickson ID (2009) Replication stress induces sister-chromatid bridging at fragile site loci in mitosis. Nat Cell Biol 11:753-760

Chan N, Koritzinsky M, Zhao H, Bindra R, Glazer PM, Powell S et al (2008) Chronic hypoxia decreases synthesis of homologous recombination proteins to offset chemoresistance and radioresistance. Cancer Res 68:605-614

Chen L, Nievera CJ, Lee AY, Wu X (2008) Cell cycle-dependent complex formation of BRCA1.CtIP.MRN is important for DNA double-strand break repair. J Biol Chem 283:7713-7720

Claybon A, Karia B, Bruce C, Bishop AJ (2010) PARP1 suppresses homologous recombination events in mice in vivo. Nucleic Acids Res 38:7538-7545

Conilleau S, Takizawa Y, Tachiwana H, Fleury F, Kurumizaka H, Takahashi M (2004) Location of tyrosine 315, a target for phosphorylation by cAbl tyrosine kinase, at the edge of the subunit-subunit interface of the human Rad51 filament. J Mol Biol 339:797-804

Cousineau I, Abaji C, Belmaaza A (2005) BRCA1 regulates RAD51 function in response to DNA damage and suppresses spontaneous sister chromatid replication slippage: implications for sister chromatid cohesion, genome stability, and carcinogenesis. Cancer Res 65:11384-11391

Cousineau I, Belmaaza A (2007) BRCA1 haploinsufficiency, but not heterozygosity for a BRCA1-truncating mutation, deregulates homologous recombination. Cell Cycle 6:962-971

Daboussi F, Dumay A, Delacote F, Lopez BS (2002) DNA doublestrand break repair signalling: the case of RAD51 post-translational regulation. Cell Signal 14:969-975

Deming PB, Cistulli CA, Zhao H, Graves PR, Piwnica-Worms H, Paules RS et al (2001) The human decatenation checkpoint. Proc Natl Acad Sci USA 98:12044-12049

Donoho G, Brenneman MA, Cui TX, Donoviel D, Vogel H, Goodwin EH et al (2003) Deletion of Brca2 exon 27 causes hypersensitivity to DNA crosslinks, chromosomal instability, and reduced life span in mice. Genes Chromosomes Cancer 36:317-331

Eszterhas SK, Bouhassira EE, Martin DI, Fiering S (2002) Transcriptional interference by independently regulated genes occurs in any relative arrangement of the genes and is influenced by chromosomal integration position. Mol Cell Biol 22:469-479

Evers B, Jonkers J (2006) Mouse models of BRCA1 and BRCA2 deficiency: past lessons, current understanding and future prospects. Oncogene 25:5885-5897

Forget AL, Kowalczykowski SC (2010) Single-molecule imaging brings Rad51 nucleoprotein filaments into focus. Trends Cell Biol 20:269-276

Friedberg EC, Meira LB (2006) Database of mouse strains carrying targeted mutations in genes affecting biological responses to DNA damage Version 7. DNA Repair (Amst) 5:189-209 
Golding SE, Rosenberg E, Khalil A, McEwen A, Holmes M, Neill S et al (2004) Double strand break repair by homologous recombination is regulated by cell cycle-independent signaling via ATM in human glioma cells. J Biol Chem 279:15402-15410

Greenberg RA, Sobhian B, Pathania S, Cantor SB, Nakatani Y, Livingston DM (2006) Multifactorial contributions to an acute DNA damage response by BRCA1/BARD1-containing complexes. Genes Dev 20:34-46

Groth A, Rocha W, Verreault A, Almouzni G (2007) Chromatin challenges during DNA replication and repair. Cell 128:721-733

Gudmundsdottir K, Ashworth A (2006) The roles of BRCA1 and BRCA2 and associated proteins in the maintenance of genomic stability. Oncogene 25:5864-5874

Halazonetis TD, Gorgoulis VG, Bartek J (2008) An oncogeneinduced DNA damage model for cancer development. Science 319:1352-1355

Harper JW, Elledge SJ (2007) The DNA damage response: ten years after. Mol Cell 28:739-745

Henikoff S (1998) Conspiracy of silence among repeated transgenes. Bioessays 20:532-535

Hong S, Pusapati RV, Powers JT, Johnson DG (2006) Oncogenes and the DNA damage response: Myc and E2F1 engage the ATM signaling pathway to activate p53 and induce apoptosis. Cell Cycle 5:801-803

Hughes-Davies L, Huntsman D, Ruas M, Fuks F, Bye J, Chin SF et al (2003) EMSY links the BRCA2 pathway to sporadic breast and ovarian cancer. Cell 115:523-535

Igoucheva O, Alexeev V, Yoon K (2006) Differential cellular responses to exogenous DNA in mammalian cells and its effect on oligonucleotide-directed gene modification. Gene Ther 13:266-275

Jasin M (2002) Homologous repair of DNA damage and tumorigenesis: the BRCA connection. Oncogene 21:8981-8993

Jazayeri A, Falck J, Lukas C, Bartek J, Smith GC, Lukas J et al (2006) ATM- and cell cycle-dependent regulation of ATR in response to DNA double-strand breaks. Nat Cell Biol 8:37-45

Kastan MB, Bartek J (2004) Cell-cycle checkpoints and cancer. Nature 432:316-323

Kenemans P, Verstraeten RA, Verheijen RH (2004) Oncogenic pathways in hereditary and sporadic breast cancer. Maturitas 49:34-43

Le Page F, Randrianarison V, Marot D, Cabannes J, Perricaudet M, Feunteun $J$ et al (2000) BRCA1 and BRCA2 are necessary for the transcription-coupled repair of the oxidative 8-oxoguanine lesion in human cells. Cancer Res 60:5548-5552

Lemelin JF, Abaji C, Cousineau I, Belmaaza A (2005) Disruption of p53 by the viral oncoprotein HPV16-E6 does not deregulate chromosomal homologous recombination in a transcriptional interference-free assay system. Cell Cycle 4:831-837

Litman R, Peng M, Jin Z, Zhang F, Zhang J, Powell S et al (2005) $\mathrm{BACH} 1$ is critical for homologous recombination and appears to be the Fanconi anemia gene product FANCJ. Cancer Cell $8: 255-265$

Lomonosov M, Anand S, Sangrithi M, Davies R, Venkitaraman AR (2003) Stabilization of stalled DNA replication forks by the BRCA2 breast cancer susceptibility protein. Genes Dev 17:3017-3022

Marmorstein LY, Ouchi T, Aaronson SA (1998) The BRCA2 gene product functionally interacts with p53 and RAD51. Proc Natl Acad Sci USA 95:13869-13874

Mazloum N, Zhou Q, Holloman WK (2007) DNA binding, annealing, and strand exchange activities of Brh2 protein from Ustilago maydis. Biochemistry 46:7163-7173

Meyn MS (1997) Chromosome instability syndromes: lessons for carcinogenesis. Curr Top Microbiol Immunol 221:71-148
Morimatsu M, Donoho G, Hasty P (1998) Cells deleted for Brca2 $\mathrm{COOH}$ terminus exhibit hypersensitivity to gamma-radiation and premature senescence. Cancer Res 58:3441-3447

Moynahan ME, Jasin M (2010) Mitotic homologous recombination maintains genomic stability and suppresses tumorigenesis. Nat Rev Mol Cell Biol 11:196-207

Olson E, Nievera CJ, Liu E, Lee AY, Chen L, Wu X (2007) The Mre11 complex mediates the S-phase checkpoint through an interaction with replication protein A. Mol Cell Biol 27:6053-6067

Petalcorin MI, Sandall J, Wigley DB, Boulton SJ (2006) CeBRC-2 stimulates D-loop formation by RAD-51 and promotes DNA single-strand annealing. J Mol Biol 361:231-242

Petiniot LK, Weaver Z, Vacchio M, Shen R, Wangsa D, Barlow C et al (2002) RAG-mediated V(D)J recombination is not essential for tumorigenesis in Atm-deficient mice. Mol Cell Biol 22:3174-3177

Raouf A, Brown L, Vrcelj N, To K, Kwok W, Huntsman D et al (2005) Genomic instability of human mammary epithelial cells overexpressing a truncated form of EMSY. J Natl Cancer Inst 97:1302-1306

Scully R, Livingston DM (2000) In search of the tumour-suppressor functions of BRCA1 and BRCA2. Nature 408:429-432

Shen WH, Balajee AS, Wang J, Wu H, Eng C, Pandolfi PP et al (2007) Essential role for nuclear PTEN in maintaining chromosomal integrity. Cell 128:157-170

Shiloh Y (2003) ATM and related protein kinases: safeguarding genome integrity. Nat Rev Cancer 3:155-168

Sleeth KM, Sorensen CS, Issaeva N, Dziegielewski J, Bartek J, Helleday T (2007) RPA mediates recombination repair during replication stress and is displaced from DNA by checkpoint signalling in human cells. J Mol Biol 373:38-47

Sorensen CS, Hansen LT, Dziegielewski J, Syljuasen RG, Lundin C, Bartek J et al (2005) The cell-cycle checkpoint kinase Chk1 is required for mammalian homologous recombination repair. Nat Cell Biol 7:195-201

Stauffer ME, Chazin WJ (2004) Physical interaction between replication protein A and Rad51 promotes exchange on singlestranded DNA. J Biol Chem 279:25638-25645

Stiff T, Walker SA, Cerosaletti K, Goodarzi AA, Petermann E, Concannon P et al (2006) ATR-dependent phosphorylation and activation of ATM in response to UV treatment or replication fork stalling. EMBO J 25:5775-5782

Thorslund T, West SC (2007) BRCA2: a universal recombinase regulator. Oncogene 26:7720-7730

Venkitaraman AR (2002) Cancer susceptibility and the functions of BRCA1 and BRCA2. Cell 108:171-182

Villemure JF, Abaji C, Cousineau I, Belmaaza A (2003) MSH2deficient human cells exhibit a defect in the accurate termination of homology-directed repair of DNA double-strand breaks. Cancer Res 63:3334-3339

Villemure JF, Belmaaza A, Chartrand P (1997) The processing of DNA ends at double-strand breaks during homologous recombination: different roles for the two ends. Mol Gen Genet 256:533-538

Villemure JF, Savard N, Belmaaza A (2001) Promoter suppression in cultured mammalian cells can be blocked by the chicken betaglobin chromatin insulator $5^{\prime} \mathrm{HS} 4$ and matrix/scaffold attachment regions. J Mol Biol 312:963-974

Vogelstein B, Kinzler KW (2004) Cancer genes and the pathways they control. Nat Med 10:789-799

Walsh T, King MC (2007) Ten genes for inherited breast cancer. Cancer Cell 11:103-105

Wang H, Powell SN, Iliakis G, Wang Y (2004) ATR affecting cell radiosensitivity is dependent on homologous recombination 
repair but independent of nonhomologous end joining. Cancer Res 64:7139-7143

Wang Y, Cortez D, Yazdi P, Neff N, Elledge SJ, Qin J (2000) BASC, a super complex of BRCA1-associated proteins involved in the recognition and repair of aberrant DNA structures. Genes Dev 14:927-939

Weaver BA, Silk AD, Montagna C, Verdier-Pinard P, Cleveland DW (2007) Aneuploidy acts both oncogenically and as a tumor suppressor. Cancer Cell 11:25-36

Welcsh PL, King MC (2001) BRCA1 and BRCA2 and the genetics of breast and ovarian cancer. Hum Mol Genet 10:705-713

Westermark UK, Reyngold M, Olshen AB, Baer R, Jasin M, Moynahan ME (2003) BARD1 participates with BRCA1 in homology-directed repair of chromosome breaks. Mol Cell Biol 23:7926-7936

Wong JM, Ionescu D, Ingles CJ (2003) Interaction between BRCA2 and replication protein $\mathrm{A}$ is compromised by a cancer-predisposing mutation in BRCA2. Oncogene 22:28-33

Xia B, Sheng Q, Nakanishi K, Ohashi A, Wu J, Christ N et al (2006) Control of BRCA2 cellular and clinical functions by a nuclear partner, PALB2. Mol Cell 22:719-729

Yajima H, Lee KJ, Chen BP (2006) ATR-dependent phosphorylation of DNA-dependent protein kinase catalytic subunit in response to UV-induced replication stress. Mol Cell Biol 26:7520-7528
Yang YG, Saidi A, Frappart PO, Min W, Barrucand C, Dumon-Jones $\mathrm{V}$ et al (2006) Conditional deletion of Nbs1 in murine cells reveals its role in branching repair pathways of DNA doublestrand breaks. EMBO J 25:5527-5538

Ye X, Franco AA, Santos H, Nelson DM, Kaufman PD, Adams PD (2003) Defective $S$ phase chromatin assembly causes DNA damage, activation of the $\mathrm{S}$ phase checkpoint, and $\mathrm{S}$ phase arrest. Mol Cell 11:341-351

Yu DS, Sonoda E, Takeda S, Huang CL, Pellegrini L, Blundell TL et al (2003) Dynamic control of Rad51 recombinase by selfassociation and interaction with BRCA2. Mol Cell 12:10291041

Yuan ZM, Huang Y, Ishiko T, Nakada S, Utsugisawa T, Kharbanda S et al (1998) Regulation of Rad51 function by c-Abl in response to DNA damage. J Biol Chem 273:3799-3802

Zhang F, Ma J, Wu J, Ye L, Cai H, Xia B et al (2009) PALB2 links BRCA1 and BRCA2 in the DNA-damage response. Curr Biol 19:524-529

Zhang J, Willers H, Feng Z, Ghosh JC, Kim S, Weaver DT et al (2004) Chk2 phosphorylation of BRCA1 regulates DNA doublestrand break repair. Mol Cell Biol 24:708-718

Zhou T, Chou J, Mullen TE, Elkon R, Zhou Y, Simpson DA et al (2007) Identification of primary transcriptional regulation of cell cycle-regulated genes upon DNA damage. Cell Cycle 6:972-981 